\title{
PARADOJAS DE LAS EDUCACIONES POPULARES Y SUS ACTORES EN TIEMPOS DE GOBIERNOS PROGRESISTAS Y CORONAVIRUS
}

\section{PARADOXES OF POPULAR EDUCATIONS AND ITS ACTORS IN TIMES OF PROGRESSIVE GOVERNMENTS AND CORONAVIRUSES}

\author{
Marco Raúl Mejía*
}

RESUMO: O texto analisa impasses e perspectivas para a educação a partir dos governos progressistas latino-americanos do início dos anos 2000 , bem como os significados da pandemia de covid-19 para o campo. Posicionando os movimentos de educação popular no contexto do Sul global, o autor defende uma proposta aberta à pluralidade e à participação política dos setores populares.

Palavras-chave: Educação popular; Sul global; Crise; Mobilização.

ABSTRACT: The article analyzes impasses and perspectives for popular education within the Latin American progressive governments of the early 2000 s, as well as the meanings of the COVID-19 pandemic for the field of popular education. By placing popular education movements in the context of the global South, the author defends a proposal open to plurality and political participation by popular sectors.

Keywords: Popular education; Global South; Crisis; Mobilization.

Estas ideas eran (y serán para siempre) emprender una educación popular para dar ser a las repúblicas imaginarias que ruedan en los libros y en los congresos

Simón Rodríguez

\footnotetext{
* Graduado em Filosofia e em Letras pela Pontifícia Universidade Javeriana de Bogotá (Colômbia) e doutor pelo Projeto Interdisciplinar de Pesquisas Educacionais do Chile (PIIE). Educador popular junto aos projetos Planeta Paz, Expedición Pedagógica Nacional e Movilización Social por la Educación. Contato: marcoraulm@gmail.com
} 
Esta cita del maestro del libertador Simón Bolívar nos sirve como abrebocas para dar forma a un texto que pretende llevarnos por los caminos del acumulado de la educación popular construida en estos lares en los últimos 200 años para diferenciarla de su versión europea de dar escuela única, laica, gratuita y obligatoria a todos los hombres, como forma de incorporación en el proyecto cultural occidental. Esta cita nos permite no solo plantear que su contenido es diferente, sino que hace parte de un proyecto cultural mayor de naciones construidas para dar forma a las repúblicas en donde éstas serán construidas con todas y con todos los que habitan esta tierra.

\section{EDUCACIÓN POPULAR, UNA CONSTRUCIÓN SOCIAL Y CULTURAL DESDE EL SUR Y PARA TODAS LAS EDUCACIONES}

El acumulado decantado permitió afirmar que la educación popular es hoy una propuesta educativa con un acumulado propio que la saca de ser solo una acción intencionada en, con y desde los grupos sociales populares para convertirla en una actuación educativa intencionadamente política en la sociedad, para transformar y proponer alternativas educativas y sociales desde los intereses y los proyectos históricos de los grupos populares. En este sentido, es una propuesta en y para toda la sociedad, para ser trabajada por todos los educadores y todas las educaciones en sus múltiples dinámicas de actuación, siempre y cuando en su horizonte ético esté la apuesta por la transformación de las condiciones de opresión en esta sociedad.

Por ello, hoy esa construcción recupera la tesis muchas veces planteada en la Pedagogía del oprimido y que recupera y reelabora una idea de Fanon ${ }^{1}$ que Freire (1996, p. 41) enuncia así:

Lucha que solo tiene sentido cuando los oprimidos, en la búsqueda por la recuperación de su humanidad, que

\footnotetext{
${ }^{1}$ Frantz Fanon nació en la colonia francesa de Martinica. Estudio psiquiatría y filosofía. Participó en las luchas de resistencia francesa de la Segunda Guerra Mundial. Luego se rebeló contra el "blanqueamiento " francés. Escribe uno de los libros pioneros para mostrar la colonialidad cultural, Piel negra, mascaras blancas. Participa en las luchas de liberación en Argelia y otros lugares de África. Su obra Los condenados de la tierra es publicada después de su muerte.
} 
deviene una forma de crearla, no se sienten idealistamente opresores de los opresores, ni se transforman, de hecho, en opresores de los opresores, sino en restauradores de la realidad de ambos. Ahí radica la gran tarea humanista e histórica de los oprimidos: liberarse a sí mismos y liberar a los opresores.

En este sentido es que hemos planteado que la educación popular es un paradigma indiciario que va consolidando un cuerpo práctico teórico que lo dota de una organización conceptual y metodológica, cuyos indicios principales generadores de pensamiento serían:

- Unos antecedentes históricos que dan forma a su propuesta

- Un fundamento práctico conceptual que lo dota de un acumulado propio

- Una propuesta de epistemologías de la diversidad y desde el sur

- Unos desarrollos pedagógicos específicos

- La emergencia de procesos investigativos a partir de la práctica

- Una búsqueda identitaria de corte interdisciplinar desde lo pluriverso

Unos antecedentes históricos que dan forma a su propuesta

Es posible reconocer una visión eurocéntrica de la educación popular asociada a la modernidad, y es el esfuerzo de la reforma protestante de dotar a cada lugar con un espacio de culto y en él una escuela para aprender a leer como posibilidad de relacionarse directamente con Dios, fundamento del pensamiento protestante y para algunos pensadores, de la subjetividad moderna. Ésta se realiza a través de la lectura del libro sagrado, la Biblia, por cada uno de los fieles. Este ideal transformado se convirtió en la escuela de la Revolución Francesa, plan Condorcet, abril de 1792, del cual surge la escuela única, laica, gratuita y obligatoria que da forma a la educación pública para hombres, no para mujeres.

Esta educación se convertía en el fundamento de la igualdad y la democracia. Esa inclusión y la institucionalización de la escuela va a ser el denominado "proyecto de educación popular de la ilustración" (CÁCERES, 1964), el cual se riega por América como ideal y acompaña a muchos de los padres fundadores de las nacientes 
repúblicas. Por ello, Sarmiento (Argentina) plantea que la civilización les llega por el Río de la Plata, y la barbarie desde la Pampa.

De igual manera, Simón Rodríguez da forma a una propuesta diferente que en carta de 1804 dirigida al Concejo de Caracas Ilama de educación popular (JARAMILLO, 1998), y que luego insistirá que debemos darle forma a una educación que nos haga americanos y no europeos, y anticipándose en muchos años a las concepciones de la poscolonialidad, afirma: "La sabiduría de la Europa y la prosperidad de los Estados Unidos son dos enemigos de la libertad de pensar en América Latina" (RODRíGUEZ, 1975, p. 133). Ese antecedente no es único, tiene continuidad con Artigas, Martí y muy diversos exponentes que la investigación futura potenciará. En un seminario reciente en La Habana, mencionaban en esta perspectiva histórica a Caballero, Mea, Maceo y otros, en el contexto cubano.

A lo largo del siglo XX, ese rastro de la educación popular toma múltiples formas por diferentes caminos: las universidades populares, las luchas de los grupos originarios, los proyectos de grupos cristianos antes de Freire, y por múltiples caminos posteriores a él (MEJÍA, 2015).

\section{Un fundamento práctico conceptual que lo dota de un acumulado propio}

$\checkmark$ Su punto de partida es la realidad y su lectura crítica, para reconocer los intereses presentes en el actuar y en la producción de la vida material y simbólica de los diferentes actores para la construcción de nueva humanidad, desde una perspectiva de capacidades.

$\checkmark$ Implica una opción básica de transformación de las condiciones que producen la opresión, injusticia, explotación, dominación y exclusión de la sociedad.

$\checkmark$ Exige una opción ético-política en, desde y para los intereses de los grupos excluidos y dominados, para la pervivencia de la madre tierra.

$\checkmark$ Construye el empoderamiento de excluidos y desiguales, y propicia su participación y organización para transformar la actual sociedad en una más igualitaria, que reconozca las diferencias y la diversidad.

$\checkmark$ Construye mediaciones educativas con una propuesta pedagógica basada en procesos de negociación cultural, confrontación y diálogo de saberes.

$\checkmark$ Considera la cultura de los participantes como el escenario en el cual se dan las dinámicas de intra, inter y transculturalidad de los diferentes grupos humanos y sus relaciones con la naturaleza.

$\checkmark$ Propicia procesos de autoafirmación y construcción de subjetividades críticas y rebeldes. 
$\checkmark$ Se comprende, en estas sociedades, como un proceso, un saber prácticoteórico que se construye desde las resistencias y la búsqueda de alternativas a las diferentes dinámicas de control.

$\checkmark$ Genera procesos de producción de conocimientos, saberes y de vida con sentido para la emancipación humana y social.

$\checkmark$ Reconoce dimensiones diferentes en la producción de conocimientos y saberes, en coherencia con las particularidades de los actores y la luchas en las cuales se inscriben.

$\checkmark$ Reconstruye entidades para hacer de las reexistencias, propuestas de transformación de la sociedad.

$\checkmark$ Su apuesta por la transformación implica cambiar ya la manera de vivir en los territorios que habitamos y en las organizaciones donde militamos.

En este sentido, también ha reconfigurado la idea de lo popular del viejo entendimiento liberal que lo asocia a la masa y la educación para ella (todos), y de la contestación del discurso crítico que lo asocia a clase social, hoy enriquecida por la infinidad de dinámicas de mediación como las diversidades, las múltiples maneras de habitar los territorios en las globalizaciones, las múltiples cosmogonías con sus epistemologías, las miradas más biocéntricas que replantean el antropocentrismo básico con sus consecuencias en la manera de constituir la individuación y las subjetividades, el camino por construir lo común y la comunalidad con sus referentes éticos, es decir, lo popular se enuncia hoy desde múltiples complementariedades que hacen del concepto algo más complejo en cuanto enuncia esas diferentes maneras de ser, estar, convivir, luchar, resistir, reexistir y, ante todo, transformar.

Hoy, la educación popular sigue jalonando una construcción que se hace nueva cada día y que, desde los más variados lugares, lee y hace visibles unos troncos comunes que leen en la diferencia y la diversidad, con énfasis específicos en coherencia con los lugares sociales desde donde se enuncia, que a la vez que muestra su riqueza teórico-práctica y hace visible la vitalidad de una propuesta que no es sino que está siendo, y muestra diferentes enfoques, entradas, como parte de su respuesta a las realidades (BRANDÃO, 2017; TORES, 2016; LÁZARO, 2016). 
Una propuesta de epistemologías de la diversidad y desde el sur, fundadas en el Buen Vivir/Vivir Bien

En el desarrollo práctico, la educación popular se fue encontrando esos mundos propios que daban forma a unas existencias de humanos diferentes, culturalmente diversos en una naturaleza única, donde lo humano se reconoce como parte de ella. Constatar esto significó reconocer una historia de negación que al descubrirse permite la emergencia de la diversidad como fundamento de las nuevas opresiones que ampliaban las de clase. Allí, emerge un sur más allá de lo geográfico como una apuesta contextual, epistémica, política y conceptual.

En esta perspectiva, en las dinámicas de lo que hemos llamado las rebeldías del continente, se han ido generando esos caminos conceptuales de acción y de vida que han permitido que esas múltiples expresiones sociales, culturales, invisibilizadas por las formas "universales" de la investigación y de las ciencias sociales, se expresen para dar voz a los relatos de esos mundos pluriversos soportados en otras cosmogonías y epistemologías, que a medida que se avanza en su conocimiento y se visibilizan sus procedimientos y sentidos con resultados y valor en sus contextos, nos permitan acercarnos a reconocer otras formas de ciencia y la necesidad de su pluralización para dar cuenta de esas otras formas de saber y conocer que posibilitan la emergencia de otras cosmogonías, conocimientos, saberes, epistemologías, diferentes a las de la ciencia clásica (KUSCH, 2000).

Los territorios son constituidos en sus múltiples aspectos, no solo por las narrativas del poder sino también por las de sus habitantes, los cuales la viven, la explican y la transforman desde sus comprensiones, que la mayoría de las veces son diferentes a las de la academia clásica, en cuanto son sus luchas y resistencias las que otorgan sentidos e identidades. En esta perspectiva, la idea de praxis que reelabora desde ese sentido común y de los saberes no académicos, le van a servir como horizonte de ruptura epistemológica que lo llevará a la formulación de que, si miramos la vida de la gente, es posible distanciarse del positivismo como única manera de explicarla (FALS BORDA, 1981). 


\section{Con desarrollos pedagógicos específicos}

Los antecedentes históricos de la educación popular muestran con claridad que una particularidad de su desarrollo es que, fruto de los retos de las especificidades contextuales, culturales y de actores, se abren una variedad de propuestas metodológicas que desbordan cualquiera de los paradigmas educativos de Occidente y de los enfoques clásicos de la pedagogía en la educación formal, generándose en muchos casos propuestas inéditas y en otras recuperando aspectos de las pedagogías críticas, lo cual le ha permitido realizar una construcción propia desde las especificidades de estos territorios, y en coherencia con las dinámicas sociales y los ámbitos de individuación, socialización, vinculación a lo público, articulación a movimientos, procesos gubernamentales de masividad y nuevas tecnologías.

En ese sentido, el diálogo de saberes freireano fue reelaborado desde la confrontación de saberes y la negociación cultural como nos las muestra Ghiso (2015), al decir: "cuando hablamos de diálogo de saberes no estamos proponiendo una práctica romántica o populista, estamos planteando una ecología, una dinámica en la que los saberes y conocimientos tienen que ser recuperados, deconstruidos, resignificados y recreados sin ingenuidad".

Es muy visible ese paso de la intraculturalidad propiciada por el diálogo de saberes a la interculturalidad, dinamizada por la confrontación de saberes en el momento en el que lo otro es negado a nombre de lo universal, los saberes a nombre de la ciencia, lo comunitario a nombre del individuo y lo personal, lo multicultural a nombre de lo monocultural, los sentidos a nombre de la razón, y muchos otros dualismos que el poder ha instituido para negar o invisibilizar lo otro y forjar redes invisibles de interlocución y negación, construyendo exclusiones sobre otras epistemologías que no responden a su universalidad, generando lo que algunos han denominado "epistemicidios" (SANTOS, 2009). Como dice Ghiso (2015),

[...] cuando hablamos de negociación cultural, estamos yendo un poco más allá en el contenido de los diálogos, 
estamos tramitando la desigualdad de poderes, la diversidad de configuraciones y la diferencia de conocimientos y formas de conocer: mediante la negociación cultural se transita a nuevos aprendizajes, conocimientos y acciones. [...] Pregunta, ¿sobre qué es necesario dialogar y negociar culturalmente? La lista puede ser amplia, pero podríamos señalar los aspectos más críticos y pertinentes al ámbito en que situamos la reflexión. Estos pueden ser: los lenguajes, códigos y símbolos; sentidos, mediaciones, imágenes y representaciones, saberes técnicos, saberes histórico-culturales, aplicaciones tecnológicas e innovaciones, nuevas institucionalidades, otras lógicas del conocer, múltiples formas de expresar el conocer, diferentes opciones ético-políticas, múltiples procesos de socialización y divulgación del conocimiento, el conocimiento [mismo], sus aplicaciones, acciones colectivas y comunitarias informadas.

La emergencia de procesos investigativos a partir de la práctica

Uno de los elementos más importantes de la propuesta de la educación popular fue cuando, al darle lugar a la diferencia, la diversidad y al enfrentar las opresiones en los territorios, se vio abocada a diseñar procesos concretos para darle voz a los actores y a las dinámicas silenciadas, permitiendo sus emergencias como procesos no solo de luchas por sus derechos o resistencias, sino visibilizando formas de reexistencia que, a la vez que dignificó, le permitió construir identidades desde esa intraculturalidad como punto de partida de su pedagogía.

Estas dinámicas exigieron, en el sentido freireano, reconocer que "la investigación de la temática, repetimos, envuelve la investigación del propio pensar del pueblo. Pensar que no se da fuera de los hombres, ni en un solo hombre solo, ni en el vacío, sino entre los hombres y entre los hombres referidos a la realidad" (FREIRE, 2005). Ese ir a lo concreto de la vida de las personas, como ese lugar donde se concretan las relaciones sociales, donde se cristalizan las múltiples determinaciones, permite que la práctica se convierta en un lugar epistemológico a ser investigado, lo cual permitió impugnar el extractivismo académico que instrumentalizó comunidades, grupos y movimientos, ahora a partir una nueva 
construcción de los actores sociales que se reconocen como productores/as de saber y conocimiento desde otras lógicas, lo cual ayuda a la ampliación de la teoría investigativa en estos lares.

Para resolver este asunto, se propone la Investigación-Acción Participante como ruta para ver de qué manera los grupos populares no academizados organizan un conocimiento desde su quehacer, mostrando cómo ese saber que a veces es desdeñado como folclor, tiene su propia racionalidad y estructura de causalidad. En ese sentido, va a tener validez científica así esté por fuera del edificio formal de la ciencia clásica (FALS BORDA, 1981).

La sistematización (JARA, 2014), como propuesta, se ha convertido en el soporte de un doble ejercicio de resistencia y reexistencia, en cuanto al buscar lo subyugado en la esfera del conocimiento también le exige dar cuenta de la manera en que se da esta subyugación en la esfera de lo cultural y de lo social, y las preformatividades de lo normal y lo anormal en Occidente. Estamos ante un proceso que permite develar las opresiones ocultas en los rangos no solo de clase, sino también de etnia, género, sexualidad, edad, discapacidades, religiones, en fin, de una lógica que leyendo desde lo universal hace de ella otra forma de sometimiento a la diferencia, que conlleva profundos caminos de inequidad, y que la investigación, ligada a los procesos de lucha van a constituir en un nuevo espacio en donde se tornan posibles caminos alternativos en sus múltiples aspectos (BARRAGÁN; TORRES, 2017).

De igual manera, se fueron tomando otras experiencias investigativas que enfatizaban en las epistemologías de la práctica, experiencias desarrolladas en otros ámbitos críticos de las diferentes ciencias, y en ocasiones, realizando ejercicios de endogenización de las mismas. Allí encontramos: la investigación del lenguaje oral, las etnometodologías y las narrativas, las reautorías, las cuales potenciaron y desarrollaron la educación popular a nuevos niveles teórico-prácticos (BRANDÃO; BERLANGA; MEJÍA; RODRÍGUEZ; SUÁREZ; CENDALES; GÓMES, 2017). 
Una búsqueda identitaria de corte interdisciplinar desde lo pluriverso

El camino del reflotar de la problemática de la educación popular en este tiempo de influencia freireana, fue dándose paralela a las emergencias de otras interpretaciones y explicaciones que intentaban dar cuenta desde nuestros contextos, de elementos que también en múltiples disciplinas tenían una mirada eurocéntrica del mundo, la cual fue interpelada permitiendo el emerger de sus propios contenidos en estos lares, lo que significó no solo diferencias y explicaciones diversas, sino también confrontaciones y descalificaciones a esta manera de explicar y comprender al mundo.

Podemos afirmar, por tanto, que esas otras maneras de explicar significaron una rebeldía en el orden del saber, del conocimiento, de las epistemologías, de las metodologías de las formas universales en las maneras de producir la vida y la cultura, dando lugar a planteamientos que mostraban otros mapas para explicar estas nuevas realidades, que debían legitimarse en el debate con los conocimientos dominantes en las esferas académicas y de la institucionalidad científica (DIMENSIÓN EDUCATIVA, 2017).

Estos múltiples desarrollos permitieron construir una serie de sinergias, en donde se encontraban rizomáticamente, la teología de la liberación, la comunicación popular, la filosofía de la liberación, el teatro del oprimido, la psicología social latinoamericana, la teoría de la dependencia, el desarrollo a escala humana, el realismo mágico, el marxismo indoamericano, la investigación-acción participante, la ética de la tierra, el buen vivir/vivir bien, la colonialidad del saber y del conocimiento, y muchas otras.

Su entrecruce fue generando concepciones y prácticas que tocaron y permitieron construir otras maneras para las presencias de las fuerzas de las reexistencias que tomaron forma conceptual y académica, estableciendo un conocimiento de frontera que le significó hacer de sus vidas espacios de lucha por construir el mundo desde la especificidad de su práctica y su enunciación como mundos en conflicto. 
Estas múltiples expresiones lograron abrir un amplio campo que ha introducido discusiones y elaboraciones propias a las que, de igual manera, se les fue exigiendo una cierta rigurosidad en el tratamiento de sus asuntos, lo cual permitió reconocer que esas rebeldías no solo ocurrían al mismo tiempo en variados territorios, si no que habían sido desarrolladas desde tiempo atrás y que tenían antecedentes que debían ser buscados en las luchas populares del pasado, así como en grupos de intelectuales que acompañaron esas luchas y búsquedas en apoyo constante, y planteamientos que comenzaron a sostener la existencia de campos propios (CABALUZ, 2016).

Dos casos emblemáticos a nivel de movimiento, antecedente importante de la educación propia, es la experiencia de warisata en Bolivia (PÉREZ, 1985), y a nivel de saberes y conocimientos populares las elaboraciones de Rodolfo Kush, y muchos otros -que sería largo mencionar-, los cuales abrieron puertas y permitieron ver la necesidad del encuentro de lo pluriverso, para construir lo común en las encrucijadas que, en cada época, la historia le abre a los caminos de transformación.

Como podemos ver en esta apretada síntesis, la educación popular como expresión centenaria de rebeldía frente al patrón eurocéntrico, ha construido unas dinámicas movimentistas en el continente americano con incidencia en otros lares. Por ejemplo, los institutos Paulo Freire de Europa y Norteamérica, que se hermanan con organizaciones y movimientos a nivel mundial, buscan transformar la sociedad para hacer real que otra educación y otros mundos son posibles.

En ese sentido, en su constitución la educación popular ha generado un cuerpo teórico-práctico que arropa en su interior a diferentes actores y sus concepciones, visibilizando la amplitud de su aprehensión y la variedad de comprensiones que sobre ella se dan, por las particularidades en que están los actores, así como sus propuestas sobre la emancipación social, como puede verse en el texto de Zibechi (2017). 


\section{AMBITOS DE LAS DINÁMICAS DE LAS EDUCACIONES POPULARES}

Uno de los asuntos centrales en la configuración de la educación popular se refiere a la manera como se ha venido constituyendo con fuerza y especificidad en las diferentes manifestaciones de la socialización, así como en los variados procesos educativos formales, no formales e informales, desarrollando un diverso repertorio de propuestas metodológicas en coherencia con su apuesta pedagógica de negociación cultural y diálogo y confrontación de saberes, convirtiendo sus herramientas en dispositivos de saber y poder. Esa variedad ha llevado a que éstas no sean universales ni simplemente procedimientos técnicos, sino elementos para construir los empoderamientos de sujetos, actores, organizaciones, movimientos. En esta perspectiva ha constituido -o está en vía de constituirlos-- seis ámbitos en los cuales realiza transformaciones y construye subjetividades rebeldes y emancipadas, como lugares de actuación:

a. Ámbitos de individuación. Existen procesos de transformación que parten de y construyen subjetividades en la constitución de sujetos que se reconocen a sí mismos como seres sociales y forjan su identidad a partir de procesos de elaboración de sí mismos. Un ejemplo de esto pudiesen ser las formas del trabajo con grupos étnicos, de género, de masculinidades, de reconocer por actores su campo de práctica y de actuación cotidiana, muy fundado en la intraculturalidad.

b. Ámbitos de socialización. Son los referentes a prácticas de educadores populares que construyen y trabajan procesos e instituciones como la familia, la escuela, constituyendo una reorganización de roles, procedimientos y prácticas. Allí se dan dinámicas de interacción específica, logrando consolidar relaciones sociales transformadas en los diferentes roles que se presentan en esos diferentes espacios.

c. Ámbitos de vinculación a lo público. La negociación cultural acá se constituye para que los sujetos de las prácticas orientadas en la perspectiva de educación popular decidan convertirse en actores que llevan sus intereses colectivos para ser disputados en lo público, reconociéndolo como un escenario en construcción. Requiere un ejercicio de discernimiento y edificación de la autonomía por parte de quienes lo realizan, y, en ese sentido, la educación popular ayuda a construirlo como apuesta de los sujetos que se están convirtiendo en actores.

d. Ámbitos de vinculación a movimientos y formas organizadas. Lo público trae aparejada consigo la necesidad de encontrar los grupos desde los cuales se tejen esos imaginarios colectivos que dan forma a sus intereses y a la manera de vida de las comunidades; las políticas de actuación, como lugares en donde los 
sueños colectivos se fundan para concretar la apuesta de transformación de sus condiciones inmediatas y de la construcción de otros mundos posibles.

e. Ámbitos de construcción de procesos de gobernabilidad. Conscientes de que el poder de los grupos populares se construye y alcanza tras recorrer múltiples caminos, los educadores populares deciden desde su acumulado, y guiados por sus principios, participar en formas de gobierno que permitan la implementación de las propuestas específicas, en donde lo público popular busca ser colocado como apuesta de la sociedad, en un particular ejercicio de la política en territorios específicos, reconociendo que se está en el gobierno y no en el poder, lo cual le exige no perder el nexo con el movimiento que creó esa nueva condición.

f. El ámbito de la masividad. Una de las características de las nuevas realidades propiciadas por las transformaciones epocales en marcha y la emergencia de los lenguajes digitales es la configuración de un espacio masivo, que a su vez ha generado una serie de redes sociales y un campo virtual en donde actúan infinidad de actores. También el educador popular reconoce éste como un espacio de su actuación y elabora propuestas metodológicas en coherencia con sus apuestas pedagógicas para constituir allí, desde sus desarrollos y acumulados, un campo de actuación y de disputa de significados y de su proyecto de transformación de la sociedad.

g. Mediaciones tecnológicas generadas en lo digital y la inteligencia artificial. Las dinámicas de los tránsitos entre la tercera y la cuarta revolución industrial han generado nuevos escenarios de mediación desde los fenómenos que se constituyen a partir de nuevos sistemas culturales constituidos desde las dinámicas de los nuevos lenguajes que se conforman en el mundo de lo digital, las nuevas realidades virtuales y los procesos de mediación educativa y social que recomponen la cultura, lo cual es muy visible especialmente en los cambios sociometabólicos que se vienen dando en las culturas infantiles y juveniles. Todo trabajo crítico exige una lectura de estos asuntos para poder dar respuesta en los múltiples aspectos que comienzan a dar forma a los nuevos escenarios educativos, y allí la propuesta metodológica de la educación popular vuelve a tener un lugar muy propicio generado en el diálogo, la confrontación, la negociación cultural y la construcción de los comunes para actuar con una perspectiva de transformación de la sociedad.

\section{GOBIERNOS ALTERNATIVOS Y DE IZQUIERDA, UN ESCENARIO DE DISCUSIÓN}

El camino trazado en estos años corridos del nuevo siglo, en donde por primera vez en nuestra historia republicana tuvimos diez gobiernos progresistas (Venezuela, Brasil, Bolivia, Ecuador, Paraguay, Uruguay, Argentina, Honduras, El Salvador, México), exige un balance y una autocrítica, ya que coloca a estos movimientos frente 
a profundos dilemas de lo que ha pasado con ellos cuando llegan a la dirección de los gobiernos, posiciones que buscaban superar el neoliberalismo, situación que ha sido recurrente en cuanto el horizonte ideológico y político de ellos estaba elaborándose mientras se gobernaba, a la vez que buscaban una diferenciación y crítica al modelo capitalista.

Para las educaciones populares ha significado un reto bien importante realizar un balance de muchos de los asuntos tramitados en estos gobiernos, en cuanto muchos educadores populares participaron activamente en ellos, tanto en espacios de diseño, planificación, como en la ejecución de las políticas a través de las cuales se le dio forma a la construcción de dinámicas alternativas y configuración de ellas como políticas públicas desde nuestros horizontes transformadores y emancipadores. En este sentido, cada uno y a su manera se consideraron parte de una serie de caminos alternativos en los que se desarrollaron buscando cuestionar las formas de ese control y en especial, la manera cómo el proyecto neoliberal se afianzó en nuestros territorios.

En este sentido, cada uno y a su manera se consideraron parte de una serie de caminos alternativos de las más variadas tendencias, en los que se desarrollaron estas políticas en estos gobiernos buscando cuestionar las formas de ese control y en especial, la manera cómo el proyecto neoliberal se afianzó en nuestros territorios. El foco estuvo ubicado allí y los matices que introdujeron eran diferenciados, por lo cual creo que no es posible nombrar bajo un mismo paraguas las diferentes expresiones de ese movimiento que deben ser analizadas en forma muy particular, y es parte de una tarea más permanente y amplia de crítica y autocrítica desde los movimientos, los procesos y organizaciones que vienen participando, cuando se haga un balance más general de su contribución al avance y retroceso de estas luchas, como ya se deja ver en el debate de las más variadas posiciones (SVAMPA, 2017).

No podemos olvidar que por estas tierras predominó a lo largo de la primera mitad del siglo XX un tipo de pensamiento clásico marxista. Es famosa la intervención que en la década del 30 le hizo el Komintern a José Carlos Mariátegui por la 
"desviación" que estaba produciendo con su teoría del marxismo indoamericano, y que en tiempos de la posguerra fue construyendo un pensamiento que realizó profundos cuestionamientos a los procesos teórico-prácticos de esa izquierda clásica, y que fue decantando en rebeldías que alimentaron procesos sociales críticos al capitalismo desde unas orillas propias. Allí encontramos, entre otras: la teología de la liberación y sus dinámicas de comunidades de base y comunidades cristianas populares, la comunicación popular, que generó dinámicas de radios populares, y hoy, de uso y producción de contenidos para redes e inteligencia artificial (GUTIÉRREZ, 1971; TAMAYO, 2015; FREIRE, 1996; MEJÍA, 2017; FALS BORDA, 2018; BOFF, 2011; GUDYNAS, 2019; RUIZ, 2015; KAPLUN, 1985).

También la emergencia de los grupos étnicos, indígenas y afros que nos colocaron frente a cosmogonías que encontraron otro fundamento epistémico y filosófico para sus actuares, la investigación-acción participante (IAP) que irrumpió cuestionando la única explicación del mundo y del conocimiento de corte central al mundo europeo y norteamericano, mostrando otras maneras de acercarse al conocimiento desde el reconocimiento de los saberes. No podemos olvidar que en esta urdimbre de rebeldías epistémicas y prácticas se teje en forma inter y transdisciplinariamente la educación popular que enfrentó las miradas universales de la educación, y develó los intereses presentes en sus metodologías y pedagogías haciéndolas políticas, y muchas otras que desbordan la brevedad de este texto.

Estas dinámicas constituyeron una bifurcación de los paradigmas clásicos en educación y pedagogía (alemán, francés, anglosajón), abriendo una perspectiva latinoamericana de ellos en educación, caracterizada en la visión freireana de "no hay texto sin contexto", lo cual permitió develar cómo el carácter eurocéntrico americano era parte central del problema de las negaciones de lo diverso, lo diferente y la unidad con la naturaleza, que al constituirse en los territorios se expresaban con múltiples opresiones en educación y pedagogía.

A lo largo de nuestra América, como consecuencia de estas dinámicas nos fuimos llenando de movimientos que en la segunda mitad del siglo XX enriquecieron las luchas y retroalimentaron esas rebeldías en lo teórico y en lo práctico, lo que 
permitió mostrar las fisuras del tipo de Estados que la metrópoli quería colocar en estos territorios. Allí encontramos como algunos de ellos: el movimiento de los sin tierra del Brasil, los guerreros del agua de Bolivia, la Confederación nacional indígena del Ecuador, los piqueteros de Argentina, los campesinos e indígenas en Colombia, los pueblos jóvenes en el Perú, las luchas de la Sierra madre en México. Y muchos más, incluidas expresiones de luchas guerrilleras que desde distintas vertientes construyeron otra expresión de las luchas anticapitalistas. Todos ellos fueron colocando el territorio como el lugar en donde se produce la vida ligada a sus tradiciones, que permitió la emergencia de unas identidades más allá de las ciudadanías liberales en donde se afincaron otras formas de autonomía con una presencia de sujetos de lucha, en donde las y los jóvenes y las mujeres se hicieron centrales para generar una reconfiguración a los modos de ser de izquierda en este continente.

En el corazón de estos movimientos se fueron generando prácticas educativas que fueron la savia de esas rebeldías, que permitieron ir construyendo unos núcleos de diferenciación de los procesos educativos y pedagógicos que tomaban especificidad desde los diferentes procesos de empoderamiento de acuerdo con los territorios, actores y ámbitos generando una eclosión de las más variadas educaciones populares a lo largo y ancho del continente.

Actores y lucha que crecieron paralelos a un proyecto de poder en donde la dinámica del capitalismo en marcha a nivel global genera en los países centrales una acumulación por vía de la renta tecnológica, el trabajo inmaterial y la inteligencia artificial, en contraposición de una acumulación por re-primarización y desposesión en sus periferias, que tiene su manifestación más clara en la sobreexplotación de la naturaleza con un uso para megaminería, incluidas las necesarias para las nuevas realidades de la inteligencia artificial, como el coltán (denominada "el oro azul"), las tierras raras y otras.

Los monocultivos se riegan por el mundo para una producción de la agricultura industrial que ha venido expulsando a las comunidades originarias, suprimiendo el derecho a los bienes comunes (genética, agua, aire) acompañado de trata de 
personas, la apropiación de los bienes colectivos, y la ampliación de la violencia y corrupción (necropolítica) en busca de la renta que se genera en las dinámicas ilegales.

Es en ese marco que se da el triunfo de los gobiernos progresistas o populares que otros denominaron "del sur" y que tomaron como bandera el anti-neoliberalismo, los cuales en sus plataformas programáticas hacen defensa de las rentas naturales en una apropiación no para las transnacionales o los capitales locales sino para que sea renta nacional y pueda ser usada para avanzar en la resolución de las necesidades básicas de sus poblaciones. Para ello se generan reformas constitucionales, profundización de políticas sociales de redistribución, la centralidad del Estado se soporta en un discurso de ambientalismo progresista y popular (MESA, 2019) que otorga un lugar clave a los movimientos indígenas, afros, de mujeres y de jóvenes.

Luego de estos 20 años, la idea de lo alternativo ha sido cuestionada desde los más diversos lugares, ya que pasó de ser un referente de las luchas contra el establecimiento a dinámicas que algunos señalaban como maquilladoras del proyecto dominante, en cuanto al estar al interior de él se veía obligado a compararse en los mismos términos y condiciones; es decir, le tocó jugar en la lógica de lo que cuestionaba. Desde muchos lugares se plantea que lo que fue visto como un sueño post neoliberal terminó siendo una flexibilización del neoliberalismo que muta para dar respuesta a los ciclos políticos progresistas, permitiendo una cierta intervención estatal con algunas formas de retorno al Estado de bienestar con políticas sociales masivas (COMPOSTO; NAVARRO, 2014).

Se entra con préstamos asociados a la expansión del sector primario, la corporativización de iniciativas populares, para lo cual permitió que desde narrativas populares estas poblaciones entraran en los ciclos del consumo y de la bancarización, así como la inclusión de procesos de comercialización orientados al mercado global, con alianzas a nuevos actores del capitalismo internacional en las disputas del nuevo multilateralismo (CAMPANINI, 2014), con una mezcla de iniciativas público-privadas que en muchos casos reintrodujo las formas de 
corrupción corporativizadas de los procesos estatales y ahora colocados en la izquierda (DUSSÁN, 2017).

De forma paradójica se daban campos donde se avanzaba a pesar de los aspectos problemáticos en distintos ámbitos, uno de ellos es el de la educación. Por ejemplo, en Bolivia se alcanza a desarrollar una ley de educación, la 070, Avelino Siñani y Elizardo Pérez, en la cual se plantea en un horizonte liberador y de educación popular. De igual manera, al interior de las dinámicas de los movimientos, un ejemplo el proyecto de educación del campo del Movimiento Sin Tierra de Brasil (CALDART; BENJAMIN, 2000).

A pesar de ello, se reconoce que a su vez muchas de esas políticas tuvieron como expresión muy potente de resistencia-reexistencia, las dinámicas comunitarias que durante mucho tiempo han pervivido en los territorios y que han sido la contraparte de las políticas de la homogeneización biótica del capitalismo, visible por ejemplo en la agricultura familiar, la seguridad y soberanía alimentaria, las cadenas de trueque de semillas nativas, el comercio de productos limpios de agroquímicos, con su correlato de saberes propios en donde se ganó claridad de la manera cómo los humanos somos naturaleza y la apropiación que habían hecho de ella. Estas formas de lucha nos mostraron que el planteamiento sobre la vida que sale del paradigma cerrado de corte antropocéntrico ofrece múltiples posibilidades para construir estos caminos alternativos, muchos de ellos ya presentes en las dinámicas de vida de los sectores populares y sus organizaciones, los cuales emergieron a través de dinámicas de educación popular.

En diferentes lugares se recuperó parte de la tradición de los pueblos originarios, incorporando en sus cartas constitucionales parte de esa tradición, como aconteció en Bolivia y Ecuador con el Buen Vivir, Sumac Kausay, y Vivir Bien, Sumac Kaumaña, los cuales llevaban la búsqueda de construir otras miradas que buscaban superar la idea de desarrollo sobre la cual estaba constituido el proyecto de control.

También alcanzó una explicitación y generación de identidades en ese caminar, con diferentes expresiones y lugares de ríos, selvas, montañas, la idea de derechos de la naturaleza de estas tradiciones. Muchos de estos procesos se tramitaron hacia 
dinámicas de enriquecimiento de movimientos en ejercicio de diálogo-confrontación de saberes y negociación cultural propias de la pedagogía de la educación popular y sus dinámicas de producción de saber y conocimiento a través de la sistematización como una forma de investigar la práctica.

También ha sido visible en este tiempo cómo las luchas contra la homogeneización cultural y el eurocentrismo al hacerse visible en los diferentes ámbitos, aprovecharon el estar con el viento a favor de un Estado que les permitió su emergencia y pudimos aprender que más que un discurso por develar la colonialidad del saber y el poder, ellas estaban vivas en infinidad de prácticas de los sectores populares y sus procesos comunitarios, que se habían mantenido como resistencias y que ahora con un proceso social progresista al mando del Estado, les abrió las compuertas y les permitió emerger como reexistencia, en cuanto esas formas de lo alternativo estaba en sus matrices culturales como práctica social, y que al encontrar un discurso estatal de plurinacionalidad, pluriversidad, emergían en los territorios como formas vivas en las cuales sus imaginarios tomaban formas precisas y concretas más allá del folclor con que habían sido recogidos en gobiernos de otro signo.

En ese emerger encontramos cómo lo popular tomaba forma y contornos propios, a la vez que estaban como soporte de infinidad de prácticas, explicaciones más profundas que daban cuenta de sus cosmogonías, sus epistemologías, sus racionalidades, mostrando una re-territorialización en la cual se construye una urdimbre de tejido social en la cual los sectores y movimientos sociales siguen fundamentando su vida, en donde ella misma ya es alternativa al proyecto del capital lo cual permitió en estos años de gobiernos progresistas lograr unos desarrollos y una elaboración que permitió una ampliación de las educaciones populares que además le dio un soporte y una profundidad teórico-práctica a sus planteamientos.

En esas emergencias construye unas primeras relaciones en donde las reexistencias nos van permitiendo mostrar los contenidos de los comunes de estos tiempos para continuar la marcha de su propuesta transformadora a la vez que permitía una profundización, los contenidos y sentidos de la pedagogía como un 
hecho político. Podemos decir que, en alguna medida, esos signos de lo alternativo no son solo discursos, sino esas prácticas que a su vez no se manifiestan como formas claras y distintas sino como hábitos, costumbres, en donde las vidas de los grupos populares tejen las nuevas rebeldías y esperanzas de que otro mundo está siendo ya en sus vidas.

Por ello podemos hablar de que en los múltiples territorios las resistencias y el reconocimiento de las formas que toma allí de manera integral la vida con procesos que, bajo el alero de los llamados gobiernos progresistas en el continente, con todos sus límites, facilitaron y permitieron que emergieran los grupos populares y sus organizaciones como interlocutores críticos de los mismos, lo cual obligó a repensar la construcción de lo alternativo de estos tiempos.

Esto convirtió en algunos lugares a los movimientos como agentes principales de interlocución, dándose una paradoja, en cuanto el poder realizar esas actividades nos convirtió en agentes principales de ese proceso, en cuanto le señalaron a los gobiernos la manera cómo terminaron entrampados en las formas liberales de los derechos, la democracia, la ciudadanía, el desarrollo, el bienestar y tantas otras tan propias del proyecto del capital.

Esta situación hizo más claro el entendimiento de que ser gobierno no es tener el poder, lo cual al profundizarse en el continente mostraron que el poder y el capital no están dispuestos a reinventar las democracias si no es desde sus parámetros y que tiene una inmensa capacidad de regenerar sus viejos controles. Allí están para no ir muy lejos, Piñeira, Bolsonaro, Hernández, Duque, el Lenin ecuatoriano y otros que vienen y vendrán, para no hablar de los colocados ahí por golpes parlamentarios.

\section{EDUCACIONES Y CORONAVIRUS}

El coronavirus ha llegado para construir un tiempo maravilloso de cambio, solo que signado por las presiones del miedo y el pánico con el cual se presenta en los medios masivos y redes sociales para viralizar la muerte como alternativa de futuro. Y allí el pensamiento y la acción crítica viene para recordarnos la manera cómo nos 
colocan los escenarios modelados por el poder, en el cual buscan con el dicho que se le atribuye a la cultura alemana, de que: "los árboles no dejan ver el bosque".

Esta situación en educación ha dado paso al afán de los modernizadores para decir que el problema es que no habíamos accedido a la virtualidad y colocar allí y en sus tecnologías las soluciones, olvidando, según Unesco, que de esos 1,600 millones de niños, niñas y jóvenes de 191 países que fueron enviados a sus casas, junto con los 63 millones de maestros y maestras, 826 millones de los estudiantes no tienen acceso a computadores, y el $43 \%$ no tiene internet en casa. Esto de nuevo vuelve a ocultar una crisis estructural de la escuela y obviar la reflexión sobre la crisis profunda del sistema educativo como correlato de la manera cómo los cimientos estructurales del capitalismo son tocados, y a la manera del traje del rey desnudo de Andersen, hoy el virus nos exige comprender estos asuntos si queremos apostarles a esas nuevas construcciones desde los territorios que habitamos tienen que ser reformulados y reinventados.

Permítanme en lo corto de este escrito señalar algunos de esos asuntos a los que obliga la agenda para reinventarnos como sociedad y educadores y educadoras populares en ella. La primera enseñanza es explicarnos cómo una crisis sanitaria devino en económica, política, social y educativa, lo cual exige explicar integralmente los problemas y los asuntos de la sociedad, así como los elementos correspondientes a la ciencia y la tecnología, los cuales no se dan sin las relaciones sociales que los constituyen. Allí se pone en evidencia la crisis del modelo de civilización planteado por la globalización, en el cual el mundo entró para colocarse en la órbita de la tercera revolución industrial que contribuyó al colapso del socialismo real y a un modelo económico y político basado en los principios neoliberales abanderados por Reagan, la señora Thatcher y el mismo papa Juan Pablo II.

Allí surgió el discurso del fin de la historia, en lo que ellos consideraban la irreversibilidad del capitalismo como un sistema imperfecto, pero era el que más propiciaba la democracia y el ascenso social, gestando unas clases medias que se harían defensoras de sus conquistas de consumo, lo cual les permitiría asumir 
también los sentidos del fin de las ideologías para vivir en un mundo técnico objetivo. De igual manera, esto daba paso al tiempo del fin de las utopías.

La manifestación más clara de ello para estos tiempos se da políticamente en un mundo multilateral (USA, China, Rusia, Alemania--en tanto líder de algunos países de la Unión Europea) con una pugna interburguesa del capitalismo, visible en el mundo a través de los nacionalismos tipo los promovidos por Trump, Bolsonaro, y el capitalismo transnacionalizado que se alineó al lado de los Clinton, los Bush, Obama, y que convirtieron al resto del mundo en veleta de un mundo organizado desde las agencias multilaterales, uno de los casos es sobre el debate a la Organización Mundial de la Salud en esta crisis, en donde pareciera, con sus argumentos, que era lo que más le convenía al mundo y se abrogaban el derecho de recoger todos los intereses políticos, aun los que desarrollaron los gobiernos de signo progresista, entrampados en los procesos de acumulación por desposesión y reprimarización que se dan en la periferia, y que fueron colocados en el escenario del desarrollo y de las políticas de estabilidad en el mundo, que dieron un marco explicativo para que el coronavirus se expandiera con las características que se ha manifestado.

En esta perspectiva, la crisis sanitaria fue tomándose todos los campos, haciendo visible cómo el capitalismo que había abandonado muchas de las políticas de su Estado de Bienestar para entregarlas al mercado y a los consorcios privados, establecieron un sistema de salud que en su desmantelamiento dejaba desprotegida a la parte mayoritaria de esa población que le había servido durante toda su vida, siendo los primeros damnificados los mayores de 70 años, que tuvieron atención si contaban con medicina privada, mientras que las redes públicas se congestionaban y sacudían la ética médica de salvar vidas decidiendo como en las guerras, quién debía morir y a quién se optaba por intentar salvar.

Y allí nos dimos cuenta de que esa pandemia golpearía con más fuerza a los más pobres, a los desprotegidos de salud y con empleos informales que en el caso latinoamericanos cubre para todos los países entre el $50 \%$ y el $70 \%$ de la población. En Estados Unidos se hace visible con 45 millones de pobres y 29 millones de ellos 
sin seguro de salud. Pero, además, con un sistema médico manejado desde las farmacéuticas para curar, no para prevenir, y un sistema financiero que era alimentado por las políticas que se constituían para supuestamente "enfrentar la pandemia”.

También el virus permitió comprender que muchos que soñaban con igualdad social a través de la educación, que este tipo de capitalismo que debilitó lo público y lo común, la escuela también era profundamente frágil, como la salud y la sobrevivencia de los más pobres; y nos enseñó que una escuela hecha para las competencias en función del proceso productivo. Esta escuela había abandonado otras miradas más integrales sobre lo humano, y ella estaba tomada por el individualismo, el "exitismo", y los resultados de pruebas desde una homogeneización que se le proponía desde el STEM, el cual había sido regado por el mundo a través de los organismos multilaterales estableciendo una competencia entre países para medir rendimientos a través de pruebas hechas en el país, pero controladas internacionalmente desde la mirada de PISA. Esto permitió encontrar que la diferencia de las escuelas estaba gestada en las clases sociales que atendía.

Cuando el virus colocó la casa, el hogar como espacio para continuar la actividad educativa, también la reina de la igualdad a través del discurso meritocrático, la escuela, quedó al desnudo e hizo visible la fragilidad del derecho a la educación, que se había construido en el discurso liberal. En esa desnudez encontramos que en nuestros países la desigualdad digital es más profunda que la económica. Invito a los lectores a buscar cifras de sus países sobre índices GINI digitales y contrastarlos con los económicos. Busquen datos sobre el tipo de cobertura en redes de banda ancha y satelital, que son los lugares donde pueden ser alojadas muchas de las propuestas de plataformas para el trabajo de educación en casa (home schooling). En el mundo envió 1,700 millones de chicos y chicas a su casa, pero solo 800 estaban en condiciones de realizar el trabajo por su acceso a las herramientas o a la conexión.

Además encontramos que el proyecto del capitalismo cognitivo para consumar su cuarta revolución industrial estaba pensado para mediados y finales de la 
siguiente década (2021 a 2030), con lo que llamaban la era de la singularidad, la cual traería en su plenitud el teletrabajo, la teleeducación y la telesalud, soportadas en las grandes plataformas de la tecnología, la cual cada vez requeriría menos seres humanos para su realización, donde sus principales gestores llamarían el mundo de lo poshumano y lo transhumano. Para ello habían organizado la Universidad de la Singularidad en el Valle de Silicon y han convertido su planteamiento en un movimiento, en donde tres de sus más consumados ideólogos son Raymond Kurzweil, de Google, Tim Cook, de Apple, y Elon Musk, de Tesla.

Nos encontramos también que los cacareados "nativos digitales" solo lo eran de redes sociales, y que su consumo era el propiciado por el mercado y las redes que los tienen para generar la información como materia prima, y nos encontramos con un uso pasivo, solo para entretenimiento y comunicación con los pares, lo cual ha servido a los políticos de la supervivencia de este escandaloso sistema para alimentar la distorsión de la realidad con los "fake news", la manipulación de elecciones, la polarización a las sociedades frente a cualquier atisbo de cambio, y establecer un capitalismo de vigilancia y manipulación a través de ella.

Encontramos que las personas estaban al servicio de la tecnología, y que no podíamos pasar simplemente a ser "ferreteros" de una educación que convierte los aparatos en lo digital sin comprender sus lenguajes, sus lógicas, visibles en el big data, los algoritmos y el pensamiento computacional, y las maneras como construyen sociedad con sus mediaciones, y nos dimos cuenta que mientras el mundo se derrumbaba y se preguntaba cosas como: ¿cómo preservar la vida? ¿Cómo construir nexos de solidaridad con los sectores pobres más afectados? ¿Por qué y cómo hemos llegado a este momento en la historia de la humanidad? La escuela ahora por internet y aparatos que no son la virtualidad se volvió a llenar con el lenguaje de: "dar", "dictar", "tomar clase", solo que ahora estaba dirigido por el mundo de las transnacionales como Youtube, Webinar, Google Classroom, Microsoft y muchos otros, porque ni siquiera los más críticos entendíamos que en este tránsito entre tercera y cuarta revolución industrial se tejían otras resistencias desde el software libre. 
Entonces comprendimos que debíamos aprovechar el cuarto de hora que nos daba el virus para propiciar una desintoxicación de los procesos educativos y escolares, haciendo visible la crisis de una educación que ya estaba en estado terminal y pedía cambios urgentes antes de la pandemia. Y allí la crisis nos comenzó a mostrar otros caminos diferentes cuando la escuela lo único que hacía por las directrices de los ministerios, era enviar los mismos contenidos con los mismos procedimientos y metodologías para seguir trabajando el mismo currículo.

Y se nos apareció otra presencialidad, que nos mostró que no era posible la educación sin educar todo el cuerpo, y ella se hizo visible en la casa, que invitaba relaciones de solidaridad, de convivencia, de reconocimiento de la diversidad, de un tiempo interior al que no le habíamos dado mucha atención, de la preocupación del cuidado de los otros y las otras, y las maneras como nos relacionamos hombres y mujeres, y nos dimos cuenta que las lecciones de nuevas masculinidades la pandemia nos las exigía y ya ahora en nuestros hogares.

Esta realidad comenzaba a mostrarnos la necesidad de reinventarnos como seres humanos y la construcción de valores compartidos más allá de la carrera loca de las competencias, los estándares, el índice sintético de calidad, los derechos básicos de aprendizaje, las evaluaciones de contenidos, el ganar y perder, y como golpe más fuerte, nos hizo la pregunta de que somos parte del planeta, no sus reyes, y a comprender que también éramos naturaleza. También nos invitó a entender a esos otros, maestros y maestras, que vienen recreando su mundo con propuestas en los territorios y que ellos pueden constituirse en la semilla para que florezca la escuela de las nuevas comunidades que construirán la tensión entre ser ciudadanas y ciudadanas del mundo e hijos e hijas de la aldea, no de la de las agencias multilaterales, y reconocemos que será una construcción colectiva que dará forma a los nuevos movimientos pedagógicos de este tiempo. 


\section{LAS AGENDAS COMIENZAN A RECONSTITUIRSE}

Es urgente una crítica al hecho educativo de la globalización capitalista y neoliberal, que soporta su fundamentación en unas competencias limitadas a un saber hacer de corte productivista, en función del mundo laboral y el mercado, que reduce la mirada de lo humano a los intereses específicos que desde el control y el poder intentan convertir su visión particular en la rectora de la sociedad, y volver a hacer necesario que todo educador y educadora se plantee los asuntos de la pertinencia.

Desde nuestro entender, no es que no existan las competencias, sino que en esta mirada del control imponen una visión recortada y limitada, que desconoce que, en su base, están las capacidades (individuación) y las habilidades (subjetividad), capacidades desde donde es posible plantear una formación que construye lo humano con dignidad y sin exclusiones. Por ello pudiéramos afirmar que, en el sentido de Nussbaum (2013), la democracia está en peligro porque la manera de entender las competencias en el sistema educativo transnacionalizado ha reducido lo humano a un saber hacer limitado que subsume en una estandarización homogeneizante la diversidad, la complejidad, y la integralidad, a partir y a través de las cuales se ha constituido lo humano a lo largo de la historia, y a lo cual la educación debe dar curso en estos tiempos para hacer posible el aquí y el ahora de los por qué y para qué de lo humano en el planeta.

En este marco, hablar de capacidades en la perspectiva de la educación popular significa dar cuenta de la manera como nos hacemos humanos y de cómo la historia de la especie me coloca frente a un acumulado que dé forma en su constitución y también explica y está a la base de las desigualdades. En esta perspectiva, existen una serie de atributos que nos pertenecen por ser miembros de este grupo vivo, lo cual me da la posibilidad en cada momento y contexto de desarrollar esas posibilidades (potencias) que pueden cultural y socialmente ser dinamizadas. Desde esta mirada, estas capacidades no son solo innatas, vienen conmigo, pero deben ser trabajadas para que emerjan, de allí la importancia de la 
formación y la educación que van a ser las encargadas de darle forma a las mismas a partir de la cultura.

Decir que hacemos estas reflexiones desde la educación popular129² significa plantear las preguntas por los elementos que están a la base de la construcción de desigualdad e injusticia, y la manera como se perpetúa una condición humana que, vivida en las realidades de nuestros países, denigra de la misma y exige preguntas fundamentales sobre las democracias reales que tenemos y los regímenes políticos que las sustentan. Ello va a exigir, desde una opción de transformación y emancipación, la necesidad de leer cómo esa política pública y especialmente en educación, aunque hablen de derechos, construyen cada vez más sociedades segmentadas, fragmentadas, basadas en la inequidad, negadoras de la diversidad y de las identidades propias de ellas, la diferencia y una humanidad que cada vez más se reconoce parte de la naturaleza.

Nos dimos cuenta que era necesario que la escuela y sus actores entendieran que debía participar en los debates que se abrían por el futuro de la humanidad y de la sociedad, y en específico sobre el futuro de la democracia, que se perfilaba sobre

\footnotetext{
2 Hoy ese acumulado, que nos permite ser educadores populares en este tiempo, lo podríamos sintetizar en los siguientes aspectos:

a. Su punto de partida es la realidad, su lectura, para reconocer los intereses presentes en el actuar y en la producción de los diferentes actores

b. Implica una opción básica de transformación de las condiciones que producen la injusticia, la explotación, dominación y exclusión de la sociedad

c. Exige una opción ético-política en, desde y para los intereses de los grupos excluidos y dominados, para la pervivencia de la madre tierra

d. Construye el empoderamiento de excluidos y desiguales, y propicia su organización para transformar la actual sociedad en una más igualitaria y que reconozca las diferencias

e. Construye mediaciones educativas con una propuesta pedagógica basada en procesos de negociación cultural, confrontación y diálogo de saberes

f. Considera la cultura de los participantes como el escenario en el cual se dan las dinámicas de intraculturalidad, interculturalidad y transculturalidad de los diferentes grupos humanos

g. Propicia procesos de autoafirmación y construcción de subjetividades críticas

h. Se comprende como un proceso, un saber práctico-teórico, que se construye desde las resistencias y la búsqueda de alternativas a las diferentes dinámicas de control en estas sociedades

i. Genera procesos de producción de conocimientos, saberes y de vida con sentido para la emancipación humana y social

j. Reconoce dimensiones diferentes en la producción de conocimientos y saberes, en coherencia con las particularidades de los actores y la luchas en las cuales se inscriben

k. Plantea la necesidad de trabajar desde los derechos, las resistencias y darle forma a las reexistencias como identidad

I. Reconoce que la transformación es un ejercicio permanente y continuo que implica cambios en la vida ya, aquí y ahora
} 
modelos autoritarios de los grupos que habían triunfado en la globalización y que quieren salir ganando de la crisis, o las comunidades educativas apostábamos por la reinvención de la democracia, la cual comenzaba a mostrar sus agendas por los caminos de la redistribución y la reducción del consumo, que jalonen una renta básica universal por una agricultura desde los campesinos, que den fundamento a la biodiversidad, y establecer condonación de deudas que con la vieja mirada cristiana inaugure los años sabáticos de este tiempo. Es decir, darnos cuenta de que es posible otro mundo, regido por otros principios diferentes a creer que el crecimiento del Producto Interno Bruto es el único destino de la humanidad, y que la crisis nos pone de frente, ante esta gran oportunidad, de otras construcciones.

Cuando cruzamos estas reflexiones intentando pensar las capacidades desde la educación popular, significa recoger para estos tiempos las enseñanzas del buen vivir/vivir bien de nuestros grupos originarios, que nos invitan desde esta perspectiva a refundar la democracia y replantear el desarrollo que en su aparente discurso humanitario han sido los fundamentos de la desigualdad, ya que asentadas sobre la idea de crecimiento y progreso -entendida como posesión de bienes y riqueza individual-, han colocado un horizonte de intereses privados e individualistas a las políticas públicas. Por ello, hablar de capacidades significa preguntarnos por la manera como se constituye y se mantiene social e históricamente la integralidad de lo humano y su dignidad, también en estos tiempos de cambios sociometabólicos y de las emergencias de lo que se comienza a llamar lo transhumano y lo posthumano.

En coherencia con lo anterior, es necesario recuperar el sentido que otorga Gadamer, leyendo a Herder (GADAMER apud RíOS, s/d), a la formación cuando afirma: "El término formación designa de manera fundamental, como el modo específicamente humano de dar forma a las disposiciones y capacidades del hombre, el proceso de formación de una persona lleva implícito el desarrollo de sus potencialidades". Acogiendo esta cita, nos encontramos que pasar de las potencias a las capacidades es el asunto central y el fundamento de cualquier proceso formativo y de socialización. 
También la crisis ha ido mostrando elementos de una agenda que nos permite avizorar caminos para reinventar la educación, la escuela y la pedagogía, y también la condición humana a construir, colocándonos en las grietas del sistema que se hacen más visibles en estos momentos, y allí la necesidad de volver a resolver desde los territorios las preguntas de la pertinencia de la escuela en estos tiempos: ¿por qué escuela? ¿para qué escuela? ¿en dónde la escuela? ¿escuela para quiénes? ¿Qué escuela?, y los ¿cómo?, de la escuela.

Esto nos exigirá también llenar de nuevos contenidos el derecho liberal a la educación y ampliarlos, y construir las comunidades que elaborarán y tramitarán las nuevas mediaciones pedagógicas desde los lenguajes mosaico, que siguiendo a Jesús Martín-Barbero sean capaces de integrar los lenguajes: el oral, el escrito y el digital, y formular las capacidades y habilidades de un tiempo en el cual el cuerpo se hace central para reconocer que los autoaprendizajes pasan por la especificidad de cada una y cada uno de nosotros, y una educación que construye no solo cabezas sino la corporeidad y los lenguajes de ella en un mundo en donde ya nadie aprende por nadie. De allí la urgencia de repensar los sentidos de la educación y los proyectos educativos y pedagógicos alternativos que den forma a la reinvención de la educación y la escuela orientados por el espíritu de educación popular de Paulo Freire cuando nos decía: "la educación por sí sola no cambia la sociedad, pero sí forma a las personas que la van a transformar".

La historia de las ideas pedagógicas en estos últimos 40 años presenta importantes marcos teóricos, entre los más significativos está sin duda, la obra de Paulo Freire, con su producción por referencia, muchos educadores, principalmente de América Latina, consolidaron uno de los paradigmas más ricos de la pedagogía contemporánea, la educación popular, la gran contribución del pensamiento pedagógico latinoamericano a la pedagogía mundial, como bien lo plantea Moacir Gadotti, el estudioso de Paulo Freire. 


\section{REFERÊNCIAS}

BARRAGÁN, D.; TORRES, A., La sistematización como investigación interpretativa crítica. Bogotá: El Búho, Síntesis, 2017.

BOFF, L. Ecología, grito de la tierra, grito de los pobres. Madrid: Trotta, 2011.

BRANDÃO, C. La educación popular de ayer y de hoy. Buenos Aires: Editorial Biblos, 2017.

BRANDÃO, C.; BERLANGA, B.; MEJÍA, M. R.; RODRÍGUEZ, M.; SUÁREZ, D.; CENDALES, L.; GÓMEZ, M. Epistemologías y metodologías emergentes en investigación desde el sur. Bogotá: Ediciones desde Abajo, 2021.

CABALUZ, F. Pedagogías críticas latinoamericanas y filosofía de la liberación: potencialidades de un diálogo teórico político. Santiago: Quimantú, 2016.

CALDART, R.; BENJAMín, C. Projeto popular, escola do campo. Brasilia: Fundação Universidade do Brasilia. 2000. (vol. 3)

CAMPANINI, J. Dependencia de los capitales chinos en América Latina y Bolivia. Cochabamba: Deliberar, 2014. (vol. 1)

COMPOSTO, C.; NAVARRO, M. Claves de lectura para comprender el despojo y las luchas por los bienes comunes y naturales en América Latina. México DF: Bajo Tierra Ediciones, 2014.

DIMENSIÓN EDUCATIVA. Paulo Freire y Orlando Fals Borda: educadores populares. Revista Aportes, Bogotá, 2017.

DUSSÁN, M. El quimbo: extractivismo, despojo, ecocidio y resistencia. Bogotá. Planeta Paz, Asoquimbo, 2017.

FALS BORDA, O. Ciencia propia y colonialismo intelectual. Bogotá: Carlos Valencia Editores, 1981.

FALS BORDA, O. La ciencia y el pueblo: nuevas reflexiones sobre la investigaciónacción. Bogotá: Asociación Colombiana de Sociología, 1981.

FALS BORDA, O. Una sociología sentipensante para América Latina. Bogotá: Clacso, Siglo del Hombre, 2016.

FREIRE, P. La pedagogía del oprimido. México DF: Siglos XXI, 1996. 
GARGALLO, F. Los feminismos del Abya Yala: ideas y proposiciones de las mujeres desde 607 pueblos en nuestra América. Bogotá: Ediciones desde Abajo, 2015.

GHISO, A. Del diálogo de saberes a la negociación cultural: recuperar, deconstruir, resignificar y recrear saberes. Revista Pensamiento Popular, v. 2, p. 28-37, 2015.

GUDYNAS, E. Extractivismo y corrupción: anatomía de una íntima relación. Bogotá: Ediciones desde Abajo, 2019.

GUTIÉRREZ, G. Teología de la liberación. Lima: Centro Bartolomé de las Casas, 1971.

JARA, O. La sistematización de experiencias: práctica y teoría para otros mundos posibles. San José: Alforja-Ceaal, 2014.

JARAMILLO, R. La modernidad postergada. Bogotá: Gerardo Rivas, 1998.

KAPLUN, M. El comunicador popular. Quito: Ciespal, 1985.

$\mathrm{KUSCH}, \mathrm{R}$. El pensamiento indígena y popular en Latinoamérica. Rosario: Editorial Fundación Ross, 2000.

LÁZARO, F. Praxis política y educación popular: apuntes en torno a una pedagogía emancipatoria en las aulas del bachillerato IMPA. Buenos Aires: Naranjo en Flor, 2016.

MEJÍA, M. R. Educación y pedagogías críticas desde el Sur: cartografías de la educación popular. México DF: CEAAL, Instituto McLaren Ensenada, 2015.

MEJÍA, M. R. Educaciones y pedagogías críticas desde el Sur: cartografías de la educación popular. Buenos Aires: Editorial Crujía, 2018.

MESA, G. El ambientalismo popular. Bogotá: Ediciones desde Abajo, 2019.

MURILLO, E. Oralidad y sentidos de la formación de maestros en la Universidad Tecnológica del Chocó. Medellín: La Carreta Social, 2017.

NUSSBAUM, M. Sin fines de lucro: por qué la democracia necesita de las humanidades. Bogotá: Katz Editores, 2013.

PÉREZ, E. La escuela ayllu de Warisata. La Paz: Papeles, 1985.

RíOS, C. Un acercamiento al concepto de formación en Gadamer. Educación y Pedagogía (Universidad de Antioquia), Medellín, n. 14-15, s/d. 
RIVERA, S. Un mundo CH'IXI es posible: ensayo de un presente en crisis. La Paz: Ediciones Tinta de Limón, 2018.

RODRÍGUEZ, S. Obras completas. Caracas: Universidad Simón Rodríguez, 1975. (vol. 2)

RUIZ, J. Otras masculinidades posibles: otras formas de ser hombre. Bogotá: Ediciones desde Abajo, 2015.

SANTOS, B. S. Una epistemología del sur: la reinvención del conocimiento y la emancipación social. México DF: Siglo XXI, Clacso, 2009.

SVAMPA, M. Del cambio de época al fin del ciclo de gobiernos progresistas: extractivismo y movimientos sociales. Buenos Aires: Edhasa. 2017.

TAMAYO, J. J. Las teologías del sur: el giro descolonizador. Madrid: Editorial Trotta, 2017.

TORRES, A. La educación popular, trayectoria y actualidad. Bogotá: El Búho, 2016.

ZIBECHI, R. Movimientos sociales en América Latina, el "mundo otro" en movimiento. Bogotá: Ediciones desde Abajo, 2017.

Recebido em 21/08/2020

Aprovado em: 05/11/2020 